\title{
Educational Program for Primiparous Women About Postpartum Preventive Measures of Genital Prolapse at Woman's Health Hospital
}

\author{
Safa Ali Mohammed ${ }^{1}$, Ghadah Abd-Elrahman Mahmoud $^{2}$ \& Essam Rashad Eldeen Abd-Elhafeez ${ }^{3}$. \\ 1. Nurse specialist at Women Health Hospital, Assiut University, Egypt. \\ 2. Professor of Maternal and Newborn Health Nursing, Faculty of Nursing, Assiut University, Egypt. \\ 3. Assistant professor of Obstetrics and Gynecology, Faculty of Medicine, Assiut University, Egypt.
}

\begin{abstract}
Background: Pelvic organs prolapse is considered as one of the most common cause of reproductive health problem which influences the women's quality of life. This study aimed to assess knowledge of primiparous women about genital prolapse \& implement educational program to these women about postpartum preventive measures of genital prolapse at Woman's Health Hospital. Patients and methods: This is a quasi- experimental research design; the study was conducted at the postpartum ward and reception unit at Women's Health Hospital, Assiut University. The simple random sample included 500 Primiparous women; the data were collected through three tools: a structured interview questionnaire, pretest \&posttest and booklet. Results: That there was a statistically significant difference between pretest knowledge level and posttest knowledge level about genital prolapse with $\mathrm{p}$-value $=0.000$, the present study showed majority of women had lack of knowledge regarding preventive measures of genital prolapse Conclusions: The findings of the study showed a significant improvement in knowledge regarding preventive measures of genital prolapse. Recommendations: Implementation of educational program for maternity nurses to increases awareness about risk factors and preventive measures of genital prolapse.
\end{abstract}

\section{Keywords: Educational Program, Preventive Measures \& Genital Prolapse.}

\section{Introduction}

Vaginal delivery is considered to be a most risk factor for the development of pelvic organ prolapse, with the greatest impact occurring at first delivery. During pregnancy the associated hormonal changes soften the supporting structures in the pelvic floor making pelvic floor muscles and supporting tissues, stretchrelated injury during the second stage of labour and the use of forceps are the main causes of muscle trauma (Abdool, 2016)

Pelvic organ prolapse (POP) is defined as a downward movement of pelvic organs, which can result in progressive herniation into or through the vagina (Pelvic organ prolapse may involve the uterus (uterine prolapse), bladder prolapse (C y s t o c o e 1 e), u r e t h r a 1 prolapse (Urethrocele), Intestinal prolapse (Enterocele), rectal prolapse (Rectocele) and the apex of vagina (vaginal vault prolapse).

(Dufour, et al., 2018)

The incidence and prevalence of POP is estimated that nearly $50 \%$ of women will develop some form of prolapse and only 10-20\% of all women seek medical assistance. The prevalence of POP increases with age, with a peak incidence in women aged 60-69 .POP can be identified in up to $50 \%$ of women upon vaginal delivery (Giamnini, et al., 2018)

Pelvic organs prolapse is consider as primarily reason of reproductive health diseases which influence the women's quality of life, the actual number of prolapse is unknown because many women don't seeking medical help because the shame from the condition which affect sensitive part of the women's body(Shrestha, 2014)

Several risk factors for uterine prolapsed including congenital weakening of cervical ligaments , parity(lager baby sizes|, multiple birth, prolonged labor when the cervix is already fully dilated, forceps delivery, perineal tears, pregnancy itself contribute towards pop), aging(loss of muscle tone ) and decreased estrogen production, hysterectomy, some connective tissue disorders, congenital abnormalities, positive family history of uterine prolapsed it is Primary causes of (POP), and any chronic conditions that accompanied by a repetitive increase in intraabdominal pressure such as chronic constipation, chronic coughing smoking, obesity, heavy lifting, and early return to work labor that each of them may lead to pelvic relaxation it is secondary causes. (Abdalla, 2017 \& Dwyer et al., 2018)

Women with POP may complain from vaginal, sexual, urinary and defecatory symptoms; vaginal symptoms include sensation of pressure or feel bulging , vaginal bleeding, increased vaginal discharge, low backache dyspareunia; urinary symptoms may include urinary incontinence, frequency and incomplete emptying of the bladder; 
defecatory symptoms include incontinence of flatus or feces, straining during defecation, and sensation of incomplete emptying. All these symptoms have social implication which affects the women's quality of life (Horst, 2017)

There are a variety of treatments about POP, however the subjective symptoms of the patient are important because the decision to treat POP depends on the pain and discomfort of the patient rather than severity as assessed by physical examination.( Barber, 2018)

Many national and international non-governmental organizations (NGOs) are investing a lot of resources to find out the causes and formulate the preventive measures as well as curative strategies to deal with this problem. It is accepted that prevention should begin early in women's life and be continued to the later years. Some of the preventive measures also have a positive effect in women's general health.(Aryal et al., 2017).

Prevention strategies of POP have many components which include proper obstetric management of childbirth, perennial hygiene, taking adequate rest during postnatal period, maintain regular postnatal follow up after delivery and using appropriate contraceptive method after puerperium avoid bearing down during first stage of labor, encourage antenatal care and stop smoking pelvic muscle floor exercise (Kegel ${ }^{\text {ee }}$ s exercises), education and behavioral modification (healthy life style): maintaining a healthy weight, proper eating to avoid constipation and straining when going to the toilet, avoiding heavy lifting (Li et al., 2016 )

Regular Kegel exercises strengthen the pelvic floor muscles to a great extent and benefit women with stress incontinence and are essential to get the body back into shape after childbirth. Kegels also improve circulation in the rectal and vaginal area, speeding recovery after an episiotomy or tear during childbirth, and decreases the perineal pain commonly occurring after episiotomy (Joshi, et al., 2016)

POP is a reproductive health problem that has not received a sufficient attention despite its high prevalence. The women's reproductive health is in need to have much more care from the beginning of the motherhood until menopause to prevent the impending complications (Rashad, et al., 2019)

Nurses are the primary health care provider of the patients, to help them to express their needs, explain the importance of appropriate preventive measures and treatment in early stage, its essential that women's should have adequate knowledge about genital prolapse thus the preparation for the discharge and home care health education. Nurse can monitor and encourage the women with pelvic organ prolapse to do Customized pelvic floor exercise and use conservative therapy through counseling (Priyanka, et al .2015).

\section{Significance of study}

Genital prolapse is not considered a life threatening condition, it affects women physically, psychologically and sexually and social limitations, prolapse can be prevented by raising women awareness and knowledge regarding POP definition, causes, risk factors, proper management and preventive measures.(Rashad, et al., 2019)

The global estimates reflect prevalence of pelvic organ prolapse (POP) among women below 45 years of age ranges from 2-20\%. A USA-based epidemiological study found a prevalence of $12.9 \%$, while a Swedish study reported an $8.3 \%$ prevalence rate in women reporting a symptom of a bulge in the vagina. Examination of women increases the prevalence to $40 \%$ of women having stage 2 or more (Madhu \& Hashim 2018).

Prospective ultrasound studies of initially primiparous women revealed that the prevalence of levator ani injuries is $21 \%$ to $36 \%$ after vaginal delivery, and that these injuries correlate with prolapse symptoms (Cheryl, et al., 2017)

Incidence of uterine prolapse in Egypt is $56 \%$, Italy $5.5 \%$, Iran 53.6\%, California 1.9\%, and Pakistan $19.1 \%$,In India, nulliparous prolapse cases constitute $(1.5-2) \%$ of genital prolapse; the incidence is even higher $(5-8 \%)$ for young women who have just delivered one or two children (Virkud, 2016)

The prevalence of urinary incontinence in Egypt to be as high as $55 \%$, Data on the prevalence of genital prolapse are limited. Pelvic organ prolapse (POP) in Egypt tends to occur at earlier ages due to multi parity rate and young age at marriage (El-Azab, et al.2015)

Aim of study

This study aimed to

1. Assess knowledge of primiparous women about genital prolapse at Woman's Health Hospital

2. Implement educational program for these women about postpartum preventive measures of genital prolapse at Woman's Health Hospital

\section{Patient \& Methods \\ Technical design \\ Study design \\ Quasi experimental research design was used in this study.}

Setting

This study was conducted at postpartum ward which its capacity is (70) beds including Normal Vaginal Delivery and Cesarean Section, and at reception unit which its capacity is (10) beds at Women's Health Hospital, Total number of nurses were (20) nurses 
who were distributed in three shifts for proving postpartum care for Primiparous women.

\section{Patients}

The study included Primiparaous women who admitted to postpartum unit and reception unit in women's health hospital when they had normal vaginal birth and met the inclusion criteria during the study period.

\section{Research question}

Is the educational program for primiparous women leads to improve the women's knowledge about preventive measures of genital prolapse?

\section{Sample}

Simple random sample of primiparous women at woman`s Health Hospital. The sample was calculated using Epi-info statistical package, version 3.3 with power $80 \%$, avalue of 2.5 is chosen at the acceptable limit of precision (D) at $95 \%$ level of confidence (CI) with expected prevalence $30 \%$, and worst acceptable $55 \%$.Accordingly, sample size was estimated to be $500+10 \%$ of individuals to guard against nondespondence rate.

\section{Inclusion criteria}

- Primiparous women who had normal vaginal delivery singleton pregnancy and full term baby.

- low risk group of primiparous women.

- Willing to participate in the study.

\section{Exclusion criteria}

Primiparous women with immediate postnatal complications.

\section{Tools of the study}

\section{Study tools}

The researcher used three tools in this study (1) structured interview questionnaire for primiparous women (2) pretest and posttest (3) booklet about the general information of genital prolapse.

Tool 1: Structured Interview Questionnaire for primiparous women

(Assessment Questionnaire)

Which developed by the researcher and contains the following

\section{A. Personal data such as}

Age, residence, level of education, occupation, telephone number.

\section{B. Medical history}

Cardiovascular diseases, respiratory diseases, tumors, hepatic diseases, diabetes mellitus, gestational diabetes, irritable bowel syndrome, smoking (positive or negative), renal problems, others.

\section{Obstetrical history (current Pregnancy and labour)}

Gestational age, complication during pregnancy if present, type of labour, Type of presenting part during labour, current postpartum complications (perineal tears, postpartum bleeding) and weight of newborn.

\section{Data related to genital prolapse}

Asking about risk factors of genital prolapse (Chronic cough, Chronic constipation, Presence of spina pifida, Feeling pain after defection, Urinary urgency, Urinary incontinence during increase intra-abdominal pressure, Heaviness of pelvis, Prolonged second stage of labour, Bearing down before full cervix dilation, Apply forceps or ventouse during labour, Perineal tears, Postpartum hemorrhage, Lifting heavy objects, Standing for long time).

Tool 2: (pretest and posttest questionnaire)

Pretest and posttest assessment of women's knowledge about genital prolapse:-

Definition, causes, degrees, risk factors, signs and symptoms, preventive measures which include: (kegel exercise, dietary management, and healthy life style Satisfaction level of knowledge: was determined and the scoring system as follows:-

The scoring system regarding the women's knowledge was as follow: Score (1) for correct answer, score (0) for don't know and incorrect answer. The total score of the women's knowledge regarding genital prolapse $=49$ and it was classified into satisfied and not satisfied as follows: not satisfied level of knowledge $<50 \%$. (score up to 24), and satisfied level of knowledge $\geq 50 \%$ (score 25 - 49).

\begin{tabular}{|l|l|}
\hline \multicolumn{1}{|c|}{$\begin{array}{c}\text { Level of } \\
\text { satisfaction }\end{array}$} & \multicolumn{1}{c|}{ Score } \\
\hline Satisfied & More than 50\% of the statement \\
\hline Not satisfied & less than $50 \%$ of the statement \\
\hline
\end{tabular}

Tool 3: Booklet about the general information of genital prolapse.

It included information about definition, causes, degrees, risk factors, signs and symptoms, complications, diagnosis, medical and surgical management, preventive measures which include: (kegel exercise, dietary management, and healthy life style

\section{Administrative design}

An official permission was obtained from the director of Women's Health Hospital to proceed with this study, and also from the Ethical committee of the Faculty of Nursing, Assiut University

\section{Ethical consideration}

1. Research proposal was approved from Ethical Committee in the faculty of nursing

2. There was no risk for study subject during application of the research.

3. The study was follow common ethical principles in clinical research

4. Written consent was taken from patient or guidance that is willing to participate in the 
study, and oral consent was taken from illiterate women.

5. Confidentiality and anonymity was assured.

6. Study subjects had the right to refuse to participate and /or to withdraw from the study without any rational any time.

7. Study subject privacy was considered during collection of data

Operational design

This design involved description of preparatory phase, pilot study and procedure

Preparatory phase:

The researcher reviewed related literature of national and international text books, articles and scientific magazines. The tools were then prepared.

Validity

The tools were reviewed for validity by 3 experts in obstetrics and gynecology (medical \& nursing).

\section{Pilot study}

A pilot study was carried out on $10 \%$ of the study sample to test the clarity of the study tools, the researcher was taken 50 women to be representative of a $10 \%$ of the study sample to test the content, validity, feasibility, clarity and objectivity of the study tool. The sample of the pilot study was included in the total sample (there was minor modification)

\section{Procedure}

Data collection was carried out through four phases:

1. Interviewing phase 2. Assessment phase

3. Implementation phase 4. Evaluation phase

1- Interviewing phase: within two hours after delivery

- All primiparous women (who were delivered normally) were interviewed at the postpartum ward and reception unit at Assiut Women's Health Hospital.

- The researcher greeted the woman and introduced herself and provided an explanation of the study including its purpose, and nature of the study.

- Women were informed that completion of the study was completely voluntary. Completion of the study implied the women's consent to participate (oral consent).

- Each woman was interviewed separately to obtain personal data, medical history, asking about risk factors and postpartum outcomes then the questionnaire items were filled by the researcher.

2- Assessment phase:( pretest assessment)

- Primiparous women's knowledge about genital prolapse was assessed by pretest structured questionnaire.

- Interviewing and assessment phase took 5 minutes.
3- Implementation phase: at the same session the researcher taught the woman the knowledge about genital prolapse, preventive measures and how to apply it during 20 minutes which include teaching and practical phases.

i. Teaching phase

- Teaching program about definition, causes, risk factors, signs and symptoms, treatment, preventive measures which include: (kegel exercise, dietary management, and healthy life style)and how to apply it.

- Booklet about the general information of genital prolapse.

Practical phase

Kegel Exercisea

Kegel exercises are designed to strengthen the pelvic floor muscles. These muscles support the bladder and bowel openings in both men and women. Strengthening the muscles of the pelvic floor can aid in preventing leakage of urine or feces with coughing, sneezing, lifting, and other stressful movements. Other benefits of kegels include enhanced sexual function, conditioned muscles to make childbirth easier, decrease and/or prevent prolapse of pelvic organs, and improve the ability to pass stool and are essential to get the body back into shape after childbirth. Kegels also improve circulation in the rectal and vaginal area, speeding recovery after an episiotomy or tear during childbirth.

\section{How to do Kegel exercises}

Find the right muscles

How to contract the pelvic floor muscles; try to stop the flow of urine while going to the bathroom. Or try another technique: Insert a finger inside the vagina and try to squeeze the surrounding muscles. Then relax muscles and feel pelvic floor move down to the previous position. As muscles become stronger and become more experienced with the exercises this movement will be more pronounced.

Don't make a habit of starting and stopping your urine stream.

It can also lead to incomplete emptying of the bladder, which increases risk of a urinary tract infection.

All the patients were taught the correct technique of Kegel exercises which included squeezing Pelvic Floor Muscles for a few seconds, and then relaxing. Feeling a pull indicated that the correct muscles were being used.

\section{Steps of practicing Kegel exercises were}

(1) Identification of the muscles.

(2) Contracting the muscles correctly.

(3) Fast and slow contractions. The slow contractions of Kegel exercises help to increase the strength of the pelvic floor. These were:

1. Lifting the pelvic floor muscles for 10 seconds. 
2. Holding the muscles tight while counting up to ten.

3. Concentrating on lifting the muscles and holding the contraction for as long as possible.

4. Gradually increasing the time up to 10 seconds.

5. Relaxation of the pelvic floor muscles and rest for 10 seconds.

6. Repeating the contractions 10 times

- The researcher taught the mothers how to recognize the accurate muscle, where to imagine that trying to stop her from passing gas and trying to stop the flow of urine midstream at the same time

- Researcher told the mother to perform regular Kegel exercise during postpartum period, later pregnancy and usual.

Healthy life style and Dietary management

Researcher told the mother to maintain healthy life style

- Trying to loss of weight, reducing persistent cough by seeking medical advice when exposed to prolonged cough.

- Taking adequate rest during postnatal period, avoid standing for long time, avoid lifting heavy objects at work or at home early after delivery.

- Maintaining regular postnatal follow up after delivery and using appropriate contraceptive method after puerperium, maintaining regular antennal follow up during later pregnancy and avoid bearing down during first stage of labor.

- Researcher told the mother to modify dietary life style (eating a high fiber diet, eating green vegetables, drinking plenty of water). Prevent occurrence and management of chronic constipation (to prevent irritable bowel syndrome)

Evaluation phase :-( posttest assessment)

- Reassessment of mother's knowledge about genital prolapse by posttest evaluation, during data collection, the researcher helped women (by Arabic words) to answer the questions and explained the difficult words to get the answer, before leaving the postpartum ward and reception unit (approximately 2 hours after delivery) the researcher was interviewed the women immediate after educational program this phase took 5 minutes.

- Each procedure took about 30 minutes included pretest, educational program and posttest 'to finish this procedure by the researcher through one year.

\section{Statistical analysis}

Data entry and data analysis were done using SPSS version 22 (Statistical Package for Social Science). Data were presented as number, percentage, mean, median and standard deviation. Chi-square test and Fisher Exact test were used to compare between qualitative variables. Mann-Whitney test was used to compare quantitative variables between two groups and Kruskal Wallis Test for more than two groups, Wilcoxon Signed Rank Test was done to compare quantitative variables between before and after program in case of non-parametric data. P-value considered statistically significant when $\mathrm{P}<0.05$.

\section{Results}

Table (1): Distribution of the studied women according to their Personal data.

\begin{tabular}{|l|c|c|}
\hline & No. (500) & \% \\
\hline Age: (years) & & 20.4 \\
\hline$<20$ & 102 & 59.2 \\
\hline $20-<25$ & 296.4 \\
\hline$\geq 25$ & 102 & 20.4 \\
\hline Mean \pm SD (Range) & \multicolumn{2}{|c|}{$21.88 \pm 2.90(16.0-32.0)$} \\
\hline Residence: & \multicolumn{2}{|c|}{7} \\
\hline Rural & 387.4 \\
\hline Urban & 113 & 22.6 \\
\hline Educational level & & 4.0 \\
\hline Illiterate & 20 & 9.0 \\
\hline Read \& write & 45 & 11.0 \\
\hline Basic education & 55 & 60.4 \\
\hline Secondary & 302 & 15.6 \\
\hline University & 78 & 14.4 \\
\hline Occupation & & \\
\hline Employed & 72 & 85.6 \\
\hline Housewife & 428 & \\
\hline
\end{tabular}


Table (2): Distribution of the studied women according to their Medical history.

\begin{tabular}{|l|c|c|}
\hline \multicolumn{1}{|c|}{ Medical history } & No. (500) & \% \\
\hline None & 132 & 3.0 \\
\hline Cardiovascular diseases & 15 & 2.2 \\
\hline Respiratory diseases & 11 & 0.2 \\
\hline Tumors & 1 & 0.8 \\
\hline Hepatic diseases & 4 & 1.0 \\
\hline Diabetes mellitus & 5 & 1.4 \\
\hline Gestational diabetes & 7 & 1.8 \\
\hline Irritable bowel syndrome & 9 & 60.0 \\
\hline Passive smoking & 300 & 6.6 \\
\hline Renal problems & 33 & 2.6 \\
\hline Anemia & 13 & \\
\hline
\end{tabular}

\#more than one answer

Table (3): Distribution of the studied women according to their Risk factors for genital prolapse

\begin{tabular}{|l|c|c|}
\hline \multicolumn{1}{|c|}{ Risk factors } & No. (500) & \% \\
\hline No risk factors & 31 & 6.2 \\
\hline Chronic cough & 31 & 6.2 \\
\hline Chronic constipation & 45 & 9.0 \\
\hline Feeling pain after defection & 27 & 5.4 \\
\hline Urinary urgency & 25 & 5.0 \\
\hline Urinary incontinence during laughing & 44 & 8.8 \\
\hline Heaviness of pelvis & 32 & 6.4 \\
\hline Prolonged second stage of labour & 39 & 7.8 \\
\hline Bearing down before full cervix dilation & 269 & 53.8 \\
\hline Perineal tears & 60 & 12.0 \\
\hline Postpartum bleeding & 60 & 12.0 \\
\hline Lifting heavy objects & 90 & 18.0 \\
\hline Standing for long time & 78 & 15.6 \\
\hline
\end{tabular}

\#more than one answer

Table (4): Distribution of the studied women according to their Knowledge level.

\begin{tabular}{|c|c|c|c|c|c|}
\hline \multirow[t]{2}{*}{ Knowledge level } & \multicolumn{2}{|c|}{$\begin{array}{l}\text { Pre-test } \\
(n=500)\end{array}$} & \multicolumn{2}{|c|}{$\begin{array}{l}\text { Post-test } \\
(n=500)\end{array}$} & \multirow[t]{2}{*}{ P-value } \\
\hline & No. & $\%$ & No. & $\%$ & \\
\hline Unsatisfactory & 498 & 99.6 & 124 & 24.8 & \multirow{2}{*}{$0.000 *$} \\
\hline Satisfactory & 2 & 0.4 & 376 & 75.2 & \\
\hline Mean \pm SD & \multicolumn{2}{|c|}{$0.45 \pm 2.43$} & \multicolumn{2}{|c|}{$27.75 \pm 5.57$} & \multirow{2}{*}{$0.000 *$} \\
\hline Median (Range) & \multicolumn{2}{|c|}{$0.0(0.0-27.0)$} & \multicolumn{2}{|c|}{$28.0(4.0-49.0)$} & \\
\hline
\end{tabular}




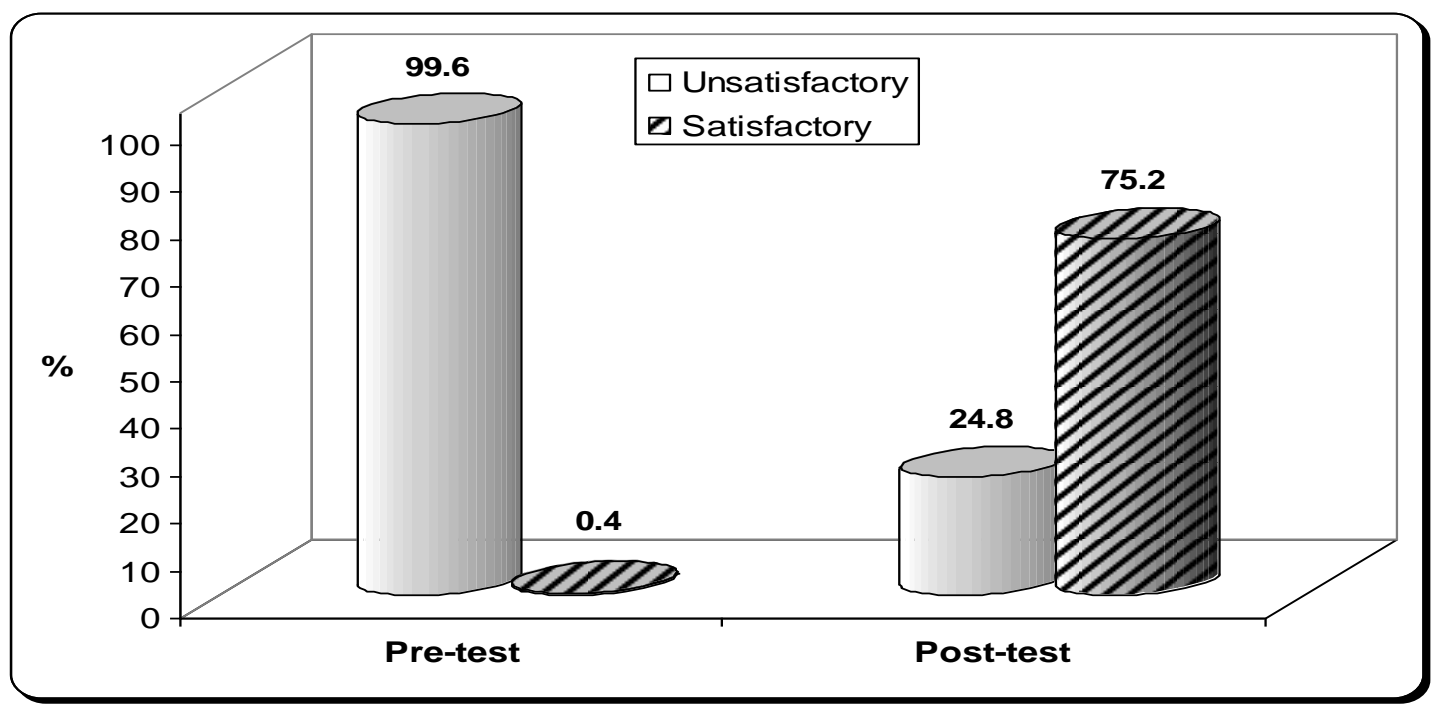

Figure (1): Distribution of the studied women according to their unsatisfactory and satisfactory level of knowledge.

Table (5): Distribution of the studied women according to their level of knowledge in post-test according to personal data.

\begin{tabular}{|c|c|c|c|c|c|}
\hline \multirow{3}{*}{ Personal data } & \multicolumn{4}{|c|}{ Knowledge level } & \multirow{3}{*}{ P-value } \\
\hline & \multicolumn{2}{|c|}{$\begin{array}{c}\text { Unsatisfactory } \\
(n=124)\end{array}$} & \multicolumn{2}{|c|}{$\begin{array}{l}\text { Satisfactory } \\
(n=376)\end{array}$} & \\
\hline & No. & $\%$ & No. & $\%$ & \\
\hline Age: (years) & & & & & \multirow{4}{*}{0.641} \\
\hline$<20$ & 28 & 27.5 & 74 & 72.5 & \\
\hline $20-<25$ & 69 & 23.3 & 227 & 76.7 & \\
\hline$\geq 25$ & 27 & 26.5 & 75 & 73.5 & \\
\hline \multicolumn{5}{|l|}{ Residence: } & \multirow{3}{*}{0.809} \\
\hline Rural & 95 & 24.5 & 292 & 75.5 & \\
\hline Urban & 29 & 25.7 & 84 & 74.3 & \\
\hline \multicolumn{5}{|c|}{ Educational level: } & \multirow{6}{*}{0.134} \\
\hline Illiterate & 8 & 40.0 & 12 & 60.0 & \\
\hline Read \& write & 14 & 31.1 & 31 & 68.9 & \\
\hline Basic education & 18 & 32.7 & 37 & 67.3 & \\
\hline Secondary & 65 & 21.5 & 237 & 78.5 & \\
\hline University & 19 & 24.4 & 59 & 75.6 & \\
\hline \multicolumn{5}{|l|}{ Occupation: } & \multirow{3}{*}{0.966} \\
\hline Employed & 18 & 25.0 & 54 & 75.0 & \\
\hline Housewife & 106 & 24.8 & 322 & 75.2 & \\
\hline
\end{tabular}

Table (1): Shows the personal data of women, it reflects that nearly two thirds respondents $(60 \%)$ were from 20-25 years age, regarding residence, more than three quarters respondents $(77.4 \%)$ were from rural area, regarding educational level, (60.4\%)of them had secondary level, and (85.6\%)respondents were housewives.

Table (2): Shows the medical history of women, it identifies that nearly two thirds respondents $(60 \%)$ had a passive smoking.
Table(3): Shows that the risk factors for genital prolapse, shows that bearing down before full cervical dilation was the most common risk factors for women, lifting heavy objects and standing for long time were common risk factors $(53.8 \%, 18.0 \%$ and $15.6 \%$ respectively).

Table (4): Shows that there was a statistically significant difference between pretest knowledge level and posttest knowledge level about genital prolapse with $\mathrm{p}$-value $(0.000)$. 
Figure (1): Shows that there are significant improvement in knowledge of the studied women

Table (5): Shows that there are no significant difference between unsatisfactory and satisfactory levels of knowledge as regarding age, residence, educational level and occupation with p-value (0.641, $0.809,0.123,0.966)$ respectively

\section{Discussion}

Genital prolapse can be prevented by raising women awareness regarding the preventive measures such as, performing Kegel exercise, maintain healthy life style ,taking adequate rest during postnatal period and use proper contraceptive method, encourage antenatal care and stop smoking, maintaining ideal body weight, avoid lifting heavy objects, avoid coughing and constipation(Elsayed et al., 2016)

This Study Aimed to assess knowledge of primiparous women about genital prolapse \& implement educational program to these women about postpartum preventive measures of genital prolapse at Woman's Health Hospital.

The present study revealed that majority of the studied women had inadequate knowledge regarding POP, the results of the present study came in the line with a descriptive study conducted by (Rashad, et al., 2019) The study was conducted at Outpatient Gynecological Clinics in the Obstetrics and Gynecology Center at Mansoura City, Egypt, on 220 women diagnosed POP who were chosen by convenient sample technique to assess women's knowledge regarding pelvic organ prolapse. They revealed that majority of the studied women (80\%) had inadequate knowledge regarding POP

Parallel to the present study findings, a descriptive study conducted by Elsayed, et al., (2016) in outpatient's clinics at Tanta University and ElMenshawy hospitals, Egypt among 200 married women to assess knowledge and practices of women regarding risk factors of uterine prolapse founded that the majority of the studied women $(95 \%)$ had poor level of knowledge regarding all items of uterine prolapse.

In addition, a cross sectional descriptive study conducted by Singh, et al, (2016)in Nepal to assess knowledge on risk factors of uterine prolapse among 185 multiparous women revealed that more than half of the studied women had inadequate knowledge.

The present study findings were partially in agreement with, a cross sectional descriptive study conducted by Shretha, et al., (2014) in Nepal, used structured questionnaire to assess knowledge and preventive measures of uterine prolapse among 4693 married women aged 14-49 , founded that the majority of the women in their study had never heard about uterine prolapse, and only more than one third of women who had ever heard about it.

In my opinion, the causes of difference between current study and previous studies might returned to that the previous studies conducted on multi parous women diagnose with advanced age POP which might have knowledge higher than primiparous women .

As regarding women's knowledge about preventive measures, The current study revealed that the vast majority of the studied women didn't have any knowledge about preventive measures of genital prolapse, the results of the present study came in the line with a descriptive study conducted by Elsayed, et al., (2016) who founded lack of women's knowledge and practices that actually taken as preventive measures to protect or prevent occurrence of uterine prolapse as the most of the studied women (81\%) didn't have any knowledge about preventive measures of uterine prolapse .

Parallel to the present study findings, preexperimental one group pre-test and post-test design conducted by Nathan et al., (2017) A semistructured questionnaire was used to assess the demographic data and knowledge regarding preventive measures of the Uterine Prolapse in 40 antenatal mothers at AIMS, Kochi. The findings of the study showed in the pre-test more than three quarters of women had inadequate knowledge, and in the posttest a significant improvement in knowledge regarding preventive measures of Uterine Prolapse among mothers.

The present study revealed that there is no association between women's total knowledge score regarding POP and the personal data of the studied women. Similarly, Shretha et al., (2014) which found that education and urban/rural residence did not associate with satisfactory knowledge about Uterine prolapse, possibly due to social norms and personal perception of Uterine Prolapse. Even educated women from urban settings do not disclose Uterine Prolapse, probably due to tradition and feelings of shame in their given social context. At the same line, Suman (2013) analysis revealed there was no significant association of posttest knowledge score with the demographic variables such as age, religion and employment and number of children The present study findings were partially in agreement with Singh, et al., (2016) who found that illiterate women aged from 25-29 years had significantly inadequate knowledge while family income had no significant association with lack of knowledge.

These findings are incongruent with Rashad et al., (2019) who found that illiterate women aged from 3550 years and had inadequate family income had 
inadequate knowledge regarding POP. Another contradicting study conducted by Mandimika, et al., (2014) who mentioned that the advanced age, moderate family income and high education were significantly associated with lacking of POP proficiency.

This may be due to education can be a major indicator for women's knowledge in the developing countries, but because POP is a neglected issue in maternity care, even in developed countries with high education there is lack of knowledge regarding this issue.

Regarding distribution of the studied women's according to their personal data, the present study revealed that nearly two thirds respondents (60\%) were from 20-25 years age, regarding residence, more than three quarters respondents $(77.4 \%)$ were from rural area, , regarding educational level, (60.4\%)of them had secondary level and (85.6\%)respondents were housewives. This result supported by Elsayed, et al., (2016) which found that The highest percent of the studied women $(89.5 \%)$ were from rural areas, slightly more than one third $(32.5 \%)$ were illiterate, and only $(11.0 \%)$ had highly education. The majority of them were house wives (81.5\%). In addition to the study Rashad et al., (2019) which found that fifths of the studied women (79.1 $\%$ ) were married and from rural area. In relation to their level of education, almost half of the studied women $(48.2 \%)$ were illiterate and almost three quarters of them $(73.6 \%)$ were housewives At the same line a descriptive research design conducted by Karki \& Neraula (2015) in Bhaktapur, Nepal, to assess the awareness regarding UVP among 118 multi parous women founded that the majority of the respondents were $<40$ years $(69.6 \%)$, were literate $(65.3 \%)$, major occupation of the mothers was house work $(63.6 \%)$.

The rational for the difference in the educational level between the present study and others findings may be due to age differences between two studies Regarding risk factors for genital prolapse, in the present study the bearing down before full cervical dilation was the most common risk factors for women, lifting heavy objects and standing for long time were common risk factors, Elsayed et al., (2016) is consistent with the finding, who found that nearly half of the studied women complained from chronic constipation and carrying heavy objects at work or at home in usual respectively The rational of difference between current study and Elsayed, et al., study might returned to that the study of Elsayed et al., conducted on married women aged 19-50 which might have risk factors higher than primiparous women .

\section{Study strengths\& limitations}

Strengths

- Sample size is large

- New research in the scientific field

- Cooperation of staff members

Limitations

There are no previous scientific studies about primiparous women as regarding genital prolapse

\section{Conclusion}

- This study concluded that there was a significant improvement in knowledge regarding preventive measures of POP in post-test

- Women had poor knowledge about genital prolapse; vast majority of them didn't know any knowledge about genital prolapse. The vast majority of women didn't know any preventive measures to prevent occurrence of genital prolapse

\section{Recommendation}

1- Implementation of parental educational program for pregnant mothers about genital prolapse and how to prevent it.

2- Implementation of educational program for maternity nurses to increases awareness about risk factors and preventive measures of genital prolapse.

3- Basic nursing education curriculum should evolve developing pelvic organ prolapse guide lines includes adequate information regarding risk factors and preventive measures of genital prolapse.

\section{References}

1. Abdalla, A., (2017): Genital Prolapse at the End Term of Pregnancy :A Case Report .Gynecol Obstet Rep:3(2):1-3

2. Abdool, Z., (2016): symptomic pelvic organ prolapse :Experience at a tertiary urogynaecology clinic, 22 (1):18-20

3. Ahmed S., El-Azab, M., Gamal M., Ghoniem, M., FACS, Szu-Yun Leu, Ph, D., Danh V., Nguyen, Ph, D., (2015): Arabic Validation of the Pelvic Organ Prolapse/Incontinence Sexual Questionnaire, IUGA-Revised (PISQ-IR) Int Urogynecol J.; 26(8): 1229-1237

4. Aryel, B., Shrestha, U., (2017): Burden of Pelvic Organ Prolapse (POP)in Nepal :Howto Prevent and Mange it? A review article, intJ Health Sci Res. 7(81):263-271

5. Barber, M., (2018): Pelvic organ prolapse. BMJ 3(54), 48-53

6. Li, Y., Gong, B., Wang, (2016) : The efficacy of pelvic floor muscle training for pelvic organ 
prolapse: a systematic review and meta-analysis, Int. Urogynecol. J. 27 (7) 981-992

7. Cheryl, B., Iglesia, M., \& Katelyn, R., (2017): Pelvic Organ Prolapse:95(3):179-185

8. Dwyerl, L., \& Kearney, R., (2018): Conservative Management of Pelvic Organ Prolapse 28(1):15-21

9. Dufour, S., Hondronicols, A., Flanigan K., (2018): Conservative Primary Care of Urinary Incontinence and Pelvic Organ Prolapse in Primary Health Care. Ann Reprod Med Treat 3(1): 1020.

10. Elsayed, F., Ahmed, M., \& Gaheen, M., (2016): Knowledge and Practices of women regarding risk factors of uterine prolapse. IOSR Journal of Nursing and Health Science (IOSRJNHS), 5(6), 60-67.

11. Giamnini, A., Eusso, E., Gano, A., (2018): Current management of pelvic organ prolapse in aging women :EMAS clinical guide:110(2018):118-123

12. Horst, W., Valle, J., Silva, J., \& Gascho, C., (2017): Pelvic organ prolapse: prevalence and risk factors in a Brazilian population. International Urogynecology Journal, 28(8), 1165-1170

13. Joshi, C., Kumer, A., Mohsin, Z., (2016): Role of Post-partum Kegel exercises in the Prevention and Cure of Stress insentience, int $\mathbf{J}$ Repord Contracept Obstet Gynecol:5(3):669673

14. Mandimika, C., Murk, W., McPencow, A., Lake, A., Wedderburn, T., Collier, C., Connell, K., \& Guess, M., (2014): Knowledge of pelvic floor disorders in a population of community-dwelling women. Am J Obstet Gynecol, 210(2), 165.e1-9.

15. Mandu, C., H,Hashim, H., (2018): Surgery for pelvic organ prolapse, www eruroprenurology .com:17(2018)119-125

16. Nathan, G., Varghese, L., \& Kanmani, J., (2017): Effectiveness of STP on Knowledge Regarding Preventive Measures of Uterine Prolapse among Mothers. Journal of Clinical and Diagnostic Research, 11(12), QC05-QC08

17. Priyanka, Kaur, S., Singh, A., \& Aggrawal, N., (2015): A Pre- experimental Study to assess the Effectiveness of Nursing Intervention Package on Management of Pelvic Organ Prolapse among Women. Nursing and Midwifery Research Journal, 11(3), 131-134

18. Rashad, M., Fadel, E., El-Nemer, A., (2019): women's knowledge regarding pelvic organ prolapse Mansoura Nursing Journal (MNJvol.6. No.1 ISSN:18235-2018).
19.Shrestha, B., Choulagai, B., Onta, S., Shrestha, K., Petzold, M., \& Krettek, A., (2014): Knowledge, prevalence and treatment practices of uterine prolapse among women of reproductive age in the Jhaukhel- Duwakot health demographic surveillance site, Bhaktapur, Nepal. J Kathamndu Med College, 3(4), 13643.

20.Singh, D., Lama, S., \& Maharjan, S., (2016): Knowledge on risk factors of uterine prolapse among reproductive age group women of Bajrabarahi Municipality of Lalitpur, Nepal. Int J Reprod Contracept Obstet Gynecol, 5(10), 3343-3348

21. Sita Kark1, Arju Neraula (2015): Awareness regarding uterovaginal prolapse among Newar parous women:1(1):15-19

22.Suman T., (2013): Effectiveness of nursing intervention package on prevention of uterovaginal prolapse among mothers. Msc thesis. Mangalore.

23. Virkud, A., (2016): conservative operation in Genital Prolapse, The journal of obstetric and gynecological of India, 66(3):144-148 